\title{
Presença extra-intestinal de cistos unizóicos de Isospora belli em paciente com SIDA. Relato de caso
}

\author{
Extraintestinal finding of Isospora belli unizoic cysts \\ in a patient with AIDS. Case report

\begin{abstract}
Jacob K. Frenkel ${ }^{1}$, Márcia Benedita de Oliveira Silva², João Carlos Saldanha², Mario Leon de Silva-Vergara², Dalmo Correia ${ }^{2}$, Cristina Hueb Barata², Eliane Lages Silva², Luis Eduardo Ramirez ${ }^{2}$ e Aluízio Prata ${ }^{2}$
\end{abstract}

\begin{abstract}
Resumo Descreve-se a presença de cistos unizóicos de Isospora belli em linfonodos mesentéricos e de gametócitos no epitélio da vesícula biliar de um paciente brasileiro de 26 anos de idade, com a Síndrome da Imunodeficiência Adquirida que recebeu tratamento, por diversas vezes, com sulfametoxazol-trimetoprim. Discute-se a importância dos cistos teciduais de I. belli como possíveis focos de resistência do parasita e a associação destes a episódios de recidivas da infecção mesmo após tratamento com medicação anticoccídios. Palavras-chaves: Isospora belli. Cistos unizóicos. SIDA.
\end{abstract}

Abstract This report describes the presence of Isospora belli unizoic cysts in mesenteric lymph nodes and of gametocytes in the gallbladder epitelium of a 26 year-old Brazilian male patient with Acquired Immune Deficiency Syndrome. This patient had received treatment for several times with sulfamethoxazole-trimethoprim. It is discussed the significance of $\mathrm{I}$. belli tissue cysts as possible foci of resistance of the parasite and their association with the infection relapse even post-treatment with anticoccidian medication.

Key-words: Isospora belli. Unizoic cysts. AIDS.

A Isospora bellié um coccídio parasita humano, cuja transmissão tem sido considerada exclusivamente pela via fecal-oral, sendo o homem seu único hospedeiro. Os sintomas da infecção, geralmente autolimitada, em pacientes imunocompetentes incluem diarréia, esteatorréia, cefaléia, febre, dor abdominal, vômito, desidratação e perda de peso. Em pacientes infectados com o vírus da imunodeficiência humana (HIV) e naqueles com a síndrome da imunodeficiência adquirida (SIDA), a infecção por Isospera belli apresenta sintomas semelhantes sendo a diarréia mais fluida, com padrão secretório e curso prolongado causando desidratação intensa e, na maioria das vezes, necessitando de hospitalização. Tem sido relatada a presença de cistos unizóicos extra-intestinais em linfonodos mesentéricos, baço e fígado de alguns pacientes com SIDA, possivelmente podem estar relacionados com recrudescência observada com freqüência em pacientes imunossuprimidos ${ }^{5,8}$. O caso a seguir descrito é o primeiro em paciente brasileiro.

\section{RELATO DO CASO}

WLT, 26 anos de idade, masculino, solteiro, natural de Araxá e procedente de Uberaba, MG, Brasil. Paciente com diagnóstico de SIDA desde 1997, quando apresentou herpes zoster, neurotoxoplasmose e diarréia por I. belli. Recebeu tratamento específico para I. belli, com melhora da sintomatologia, tendo sido iniciada a terapia anti-retroviral com zidovudina e didanosina , em uso irregular durante dois anos.

Em 1999, foi feito o diagnóstico de tuberculose pulmonar, tratada durante seis meses. Neste período foi introduzida a terapia anti-retroviral com lamivudina, estavudina e efavirenz. Em fevereiro de 2001, foi internado

\footnotetext{
1. University of New Mexico, Albuquerque, NM. 2.Faculdade de Medicina do Triângulo Mineiro. Uberaba,MG.

Trabalho realizado como auxílio da Fundação de Amparo à Pesquisa de Minas Gerais (Projeto CDS 2334/98).

Endereço para correspondência: Dr. Jacob K. Frenkel. 1252 Vallecita Drive, Santa Fé, NM 87501-8803, USA.

Recebido para publicação em 26/11/2002
}

Aceito em 23/5/2003 
com síndrome diarréica com quatro dias de evolução, causada por $I$. belli, sendo prescrito sulfamethoxazoltrimetoprim, com regressão dos sintomas. Este mesmo quadro foi observado 30 e 120 dias após sendo, em ambas ocasiões, detectada a presença de I. belli e re-introduzido o tratamento específico. Nesta época a contagem de linfócitos T foi a seguinte: CD4:208 células/ $\mathrm{mm}^{3}$, CD8: 1657 células/ $\mathrm{mm}^{3}$ e relação CD4/CD8: 0,13. Após novo episódio de síndrome diarréica em setembro de 2001, mesmo tendo recebido sulfamethoxazol-trimetoprim, a excreção de oocistos de I. belli persistiu. Foi suspensa a reposição de acido fólico e complexo $B$, considerando que suas formulações poderiam conter ácido paraminobenzóico que é um antagonista do sulfametoxazol-trimetoprim, sendo observada a negatividade de oocistos nas fezes.

Em outubro de 2001, foi internado com história de dor abdominal, vários episódios de diarréia e vômitos, desidratado, tensão arterial $80 \times 40 \mathrm{mmHg}$, freqüência cardíaca de 105 sístoles por minuto, hemoglobina $11 \mathrm{~g} \%$, hematócrito $28,7 \%$, leucócitos $6.910 / \mathrm{mm}^{3}$, plaquetas $73.000 / \mathrm{mm}^{3}$, creatinina $2 \mathrm{mg} \%$, proteínas totais $4,9 \mathrm{~g} \%$ (1,8g\% de albumina), cálcio $6,6 \mathrm{meq} / \mathrm{l}$, potássio $1,2 \mathrm{meq} / \mathrm{l}$, sódio $133 \mathrm{meq} / \mathrm{l}$, cloro $106 \mathrm{meq} / \mathrm{l}$, glicemia $71 \mathrm{mg} \%$. Durante esta internação, persistiu o quadro diarréico, com importante perda de peso, anorexia e vômitos. Os hemogramas de controle mostraram pancitopenia severa e contagem de linfócitos T CD4 de 53 células $/ \mathrm{mm}^{3}$. No vigésimo dia de internação, apresentou insuficiência respiratória, confusão mental, acidose metabólica e choque séptico, evoluindo com parada cardiorespiratória irreversível. O óbito foi atribuído à septicemia por Staphylococcus aureus. A cultura da ponta de cateter venoso isolou Staphylococcus aureus multidroga resistente.

Exame histopatológico. Foram examinados amostras de esôfago, duodeno, íleo, colon, apêndice e vesícula biliar, sendo encontrados gametócitos (macrogametócito e microgametócito) no epitélio da vesícula biliar (Figuras 1bc) e cistos unicelulares em três linfonodos, de origem mesentérica (Figuras 1a, 2abc, 3abc).

Os seis cistos tinham morfologia irregular, três

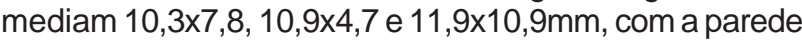
usualmente fina, mas podendo variar de 0,7 a $1,7 \mathrm{~mm}$ de espessura (Figuras 3abc). O único zoíto dentro do cisto foi bem demonstrado após coloração por hematoxilinaeosina (HE). Os outros três mediam 7,2×3,2, 7,6x2,6 e $7,8 \times 2,8 \mathrm{~mm}$. Um único núcleo aparece vesicular e o citoplasma corado uniformemente de vermelho. A área total do parasita variou de 16,0 a 17,9 $\mathrm{mm}^{2}$.

Após coloração pelo ácido periódico-Schiff (PAS) e por HE, foram vistos grânulos intensamente corados de vermelho formando 1 a 3 grupos, 2 dos quais ao redor do núcleo. A parede do vacúolo se corou mais fracamente, semelhantemente a tecido conjuntivo (Figura 2). À coloração pelo Giemsa, os cistos foram de difícil visualização, apresentando núcleo pálido e citoplasma ligeiramente eosinofílico, sendo reconhecidos pela sua forma (Figura 1a).

Abscessos de 1-2mm de diâmetro, com colônias de micrococos, foram vistos no miocárdio e na válvula mitral. Embolia séptica foi detectada no fígado, baço, rins, pâncreas, estômago, intestino delgado e nos pulmões, este último apresentando também broncopneumonia confluente. Evidenciou-se ainda orquite granulomatosa com bacilos ácool-ácidoresistentes e atrofia do epitélio germinal.

O óbito do paciente foi atribuído à septicemia aguda por Staphylococcus aureus, confirmada por hemoculturas.

\section{DISCUSSÃO}

O presente relato de isosporíase humana com localização extra-intestinal é o primeiro descrito no Brasil e, provavelmente, o quinto na literatura. Todos os casos já descritos foram associados a pacientes $\mathrm{HIV}(+) /$ SIDA e demonstraram cistos unizóicos ou monozóicos preferencialmente em linfonodos mesentéricos e traqueobronqueais, no fígado e baço além da presença de cistos teciduais na mucosa intestinal ${ }^{6} 89$. Experimentalmente, tem sido observado estágios extraintestinais de Isospora felise Isospora rivolta em linfonodos mesentéricos, fígado, baço, pulmão e cérebro de gatos jovens ${ }^{3}$.

Um dado polêmico na literatura está relacionado com a origem dos cistos unizóicos extra-intestinais evidenciados em pacientes com HIV(+)/SIDA, pois não se sabe se resultam da ingestão de oocistos ou do ciclo entérico. De acordo com a hipótese de Lindsay et $\mathrm{al}^{5}$, os cistos extra-intestinais seriam originados de merozoítos produzidos no intestino ou em outros sítios extra-intestinais, que através das vias linfáticas ou sanguineas poderiam ser disseminados. Este fato é reforçado pela presença de estágios sexuados de I. bellino epitélio da vesícula biliar associado a cistos unizóicos nos linfonodos mesentéricos evidenciados neste trabalho, assim como pelos dados de Benator et $\mathrm{al}^{1}$, que observaram estágios assexuados e sexuados no epitélio do ducto biliar e de Comin \& Santucci ${ }^{2}$ que detectaram merozoítos no lúmen intestinal, lâmina própria e dentro de canais linfáticos. Contudo, a questão permanece em aberto diante do pequeno número de casos descritos na literatura, sendo fundamental a caracterização dessas formas com técnicas de microscopia eletrônica, imunohistoquimica e/ou moleculares.

Outro fato importante observado na literatura é a freqüente occorrência de recidivas por $I$. belli, tanto em pacientes imunocompetentes como em imunossuprimidos. Segundo Lindsay et $\mathrm{al}^{5}$ as recidivas, provavelmente, seriam decorrentes da presença de zoítos quiescentes dentro de cistos extra-intestinais os quais seriam menos susceptíveis aos tratamentos anticoccídios. Esta situação é similar à observada em encefalites por toxoplasmose em pacientes com SIDA, 


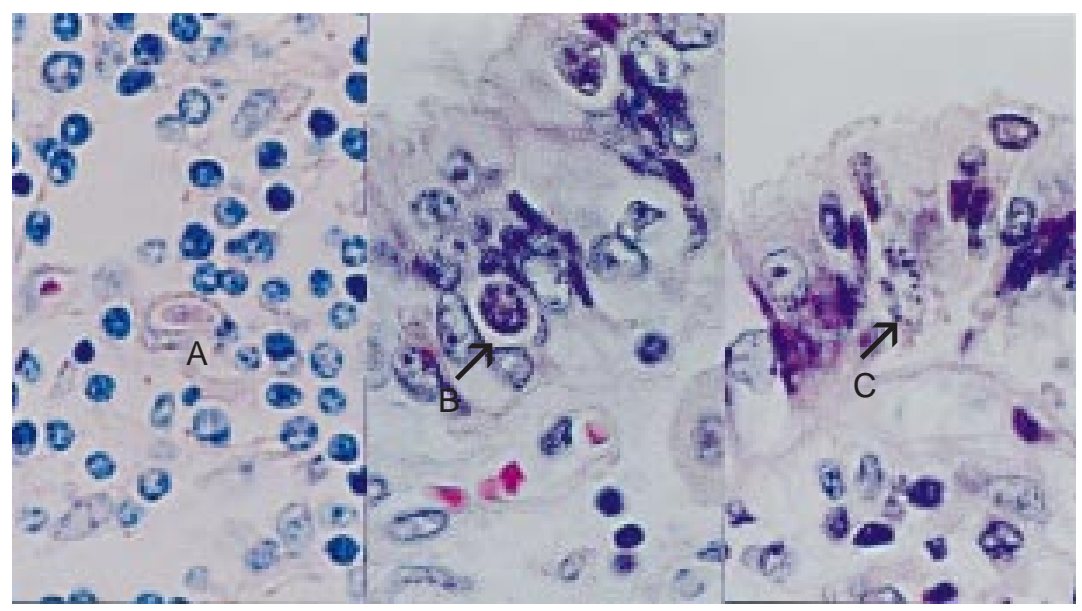

Figura 1a: Cisto monozóico do linfonodo, Giemsa, 575x; b: Macrogametócito e c: Microgametócito de Isospera belli em vesícula biliar do paciente. HE, $575 \mathrm{x}$.

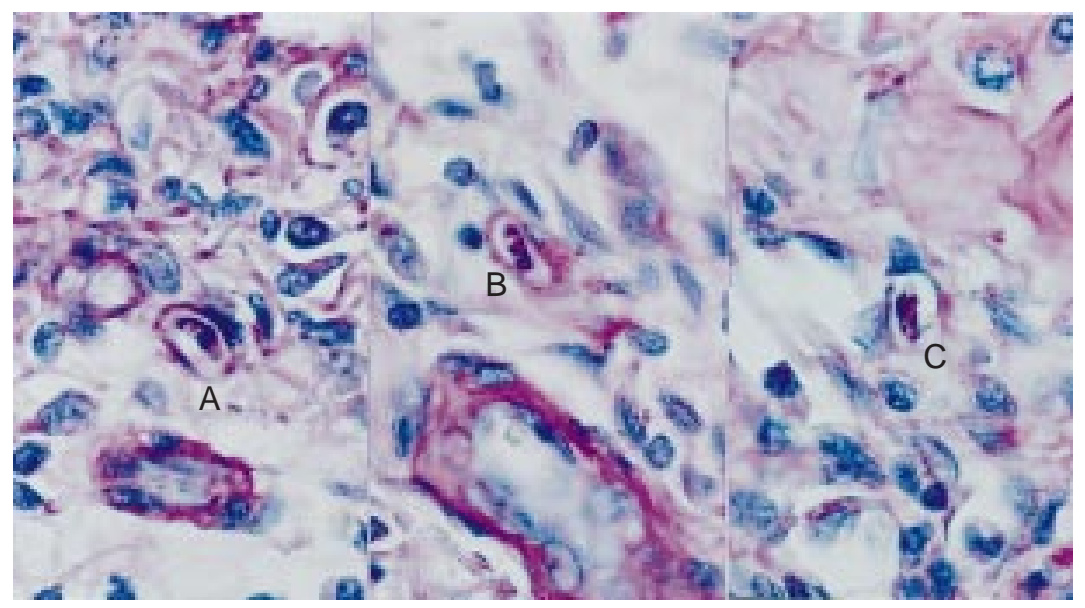

Figura 2a, b, c: Cistos unizóicos ao redor do linfonodo (a e b) ou dentro(c), PASH, $575 x$, Os grânulos PAS-positivos estão agrupados em dois ou três grupos ou estão distribuídos irregularmente.

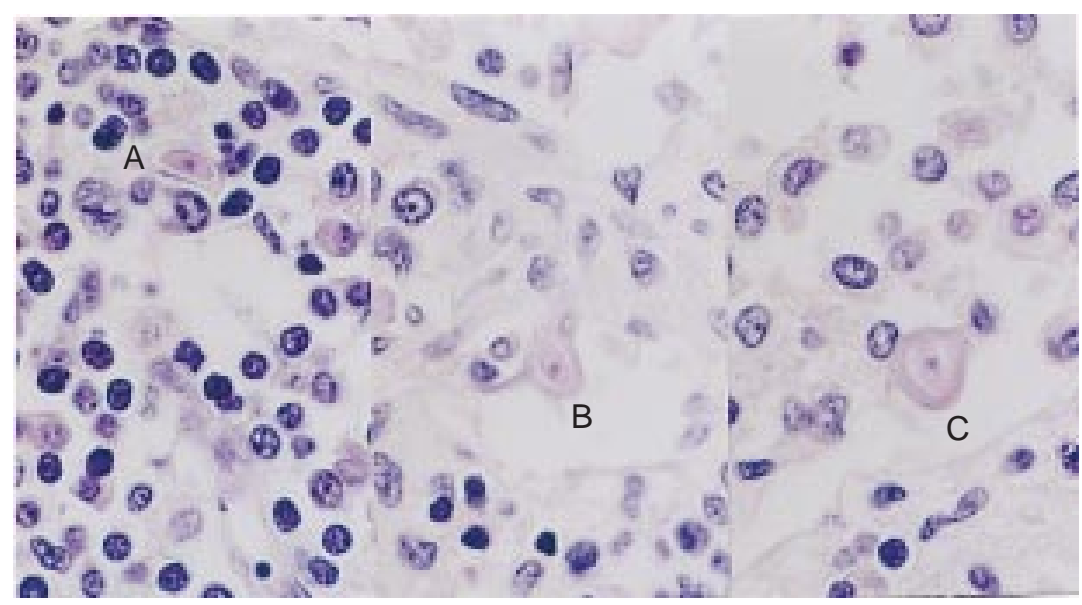

Fiqura 3a,b, c: Cistos unizóicos de linfonodos provavelmente mesentéricos do paciente, $H E, 575 x$ 
onde a recidiva é comum e é causada por estágios císticos com bradizoítos latentes ${ }^{4}$.

A importância da resposta imune celular na infecção por coccídios é bem evidenciada na criptosporidiose onde o tratamento com anti-retrovirais estimula a resposta imunológica do paciente com SIDA, aumentando o número de linfócitos CD4 que está diretamente relacionado com o controle da infecção e seus sintomas ${ }^{7}$. Entretanto, no caso aqui relatado, apesar do paciente ter sido tratado repetidas vezes com sulfamethoxazol-trimetoprim e ter recebido tratamentos anti-retrovirais apresentando índices de linfócitos T CD4 superiores a $208 / \mathrm{mm}^{3}$, a infecção persistiu com a detecção de oocistos de I. belli nas fezes. O encontro de cistos unizóicos neste paciente revela parcial sensibilidade à quimioterapia, com a persistência do parasita, fato que pode estar diretamente relacionado com a ocorrência de recidivas. De acordo com estes achados fica evidente a necessidade de mais estudos sobre a importância da resposta celular do hospedeiro em relação à infecção por l. belli e ainda, se a presença tecidual dos cistos unizóicos extra-intestinais, seria um mecanismo de escape do parasita à ação quimioterápica dos anticoccídios.

\section{AGRADECIMENTOS}

Ao Dr. Javier Lazo do Departamento de Patologia da Faculdade de Medicina do Triângulo Mineiro, por medir as células com Morphometria Leica Q500 MC e a João Norberto de Oliveira do Departamento de Histologia (Microscopia eletrônica), FMTM, pelas fotografias que acompanham este trabalho.

\section{REFERENCIAS BIBLIOGRAFICAS}

1. Benator DA, French AL, Beaudet LM, Levy CS, Orenstein JM Isospora belli infection associated with acalculous cholecystitis in a patient with AIDS. Annals of Internal Medicine 121: 663-664, 1994.

2. Comin CE, Santucci M. Submicroscopic profile of Isospora belli enteritis with in a patient with acquired immune deficiency syndrome. Ultrastructural Pathology 18: 473-482, 1994.

3. Dubey JP, Frenkel JK. Extra-intestinal stages of Isospora felis and I. rivolta (Protozoa: Eimeriiidae) in cats. The Journal of Protozoology 19:89-92, 1972.

4. Frenkel JK, Nelson BM, Arias-Stella J. Immunosuppression and toxoplasmic encephalitis: Clinical an Experimental aspects. Humam Pathology 6:97-111,1975.

5. Lindsay DS, Dubey JP, Toivio-Kinnucan MA, Michiels JF, Blagburn BL. Examination of extraintestinal tissue cysts of Isospora belli. Journal of Parasitology 83:620-625, 1997.
6. Michiels JF, Hofman P, Bernard E, Saint Paul MC, Boissy C, Mondain V, Le Fichoux Y, Loubiere R. Intestinal and extraintestinal Isospora belli infection in an AIDS patient. A second case report. Pathology Research and Practice 190:1089-1093,1994.

7. NavinTR, Weber R, Vugia DJ, Rinland D, Roberts JM, Addiss DG. Declining CD4+ T-lynphocyte counts are associated with increased risk of enteric parasitosis and chronic diarrhea: results of a 3-year longitudinal study. Journal of Acquired Immune Deficiency Syndromes and Human Retrovirology 20:154-159, 1999.

8. Restrepo C, Macher AM, Radany EH. Disseminated extraintestinal isosporiasis in a patient with acquired immune deficiency syndrome. American Journal of Clinical Pathology 87: 536-542, 1987.

9. Velasquez JN, Carnevale,S, Mariano M, Kuo LH, Caballero A, Chertcoff A, Ibañez C, Bozzini JP. Isosporosis and unizoite tissue cysts in patients with acquired immunodeficiency syndrome. Human Pathology 32: 500-505, 2001. 